\title{
Cropload Management of 'Vidal blanc' Improves Primary Bud Cold Hardiness and Maintains Berry Composition in the Lower Midwestern United States
}

\author{
Patsy E. Wilson, Douglas D. Archbold, and Joseph G. Masabni ${ }^{1}$ \\ Department of Horticulture, University of Kentucky N308-D College of \\ Agricultural Sciences, Lexington, KY 40504
}

\section{S. Kaan Kurtural ${ }^{2}$ \\ Department of Viticulture and Enology, California State University, Fresno, 2360 E. Barstow M/S VR 89, Fresno, CA 93740}

Additional index words. balanced cropping, cluster thinning, cold hardiness, French-American hybrid, Ravaz Index, warm climate viticulture

\begin{abstract}
Canopy architecture, yield components, berry composition, pruning weight, Ravaz Index, and midwinter primary bud cold hardiness of own-rooted 'Vidal blanc' (Vitis vinifera $\times$ Vitis rupestris) were measured in response to balanced pruning formula treatments of 20, 30, or 40 nodes retained for the first $454 \mathrm{~g}$ of dormant pruning weight and an additional 10 nodes for each additional $454 \mathrm{~g}$ and three cluster thinning levels of one, two, and two+ clusters per shoot in 2006 and 2007. Although the pruning formula affected the distance between shoots along the canopy, and the number of count shoots per hectare, the canopy leaf layer numbers were unaffected in either year. Application of the pruning formula did not affect components of yield in either year. However, the number of clusters and yield per vine were affected by cluster thinning treatments where they increased linearly with the decrease in its severity, explaining $73 \%$ and $77 \%$ of total variance in yield in $\mathbf{2 0 0 6}$ and 2007, respectively. Pruning formula or cluster thinning did not affect berry composition substantially. Cluster thinning improved the percentage of mature nodes on shoots before a killing frost in both years. Cluster thinning to one or two clusters per shoot also improved the lethal temperature killing $50 \%$ of the primary buds compared with no cluster thinning in both years of the study. Mature wood weight and total pruning weight displayed a quadratic response to cluster thinning where two clusters per shoot had the greatest weight for both, whereas pruning formula had no effect on pruning weight. Optimum fruit weight-pruning weight ratio was achieved with the $30+10$ pruning formula and two clusters per shoot cluster thinning treatments in both years of the study. The results of this study provide valuable information for growers of interspecific hybrids such as 'Vidal blanc' in the lower midwestern United States as well as in other regions with long, warm growing seasons. Balanced pruning to 30 nodes per $454 \mathrm{~g}$ of dormant prunings and cluster thinning to two clusters per shoots optimized yield, maintained fruit composition, improved primary bud cold hardiness, and achieved an optimum fruit weight-to-pruning weight ratio of $10.0 \mathrm{~kg} \cdot \mathrm{kg}^{-1}$. Thus, this approach should be used for 'Vidal blanc' in the lower midwestern United States to sustain production.
\end{abstract}

'Vidal blanc' (Vitis vinifera $\times$ Vitis rupestris) is the most important white wine grape cultivar planted in Kentucky as a result of its adaptability to climate and soil and increased local demand. However, there is

Received for publication 13 Mar. 2014. Accepted for publication 29 May 2014.

This study was in part funded through competitive grant funds made available by the Kentucky Wine and Grape Resources Council.

We express sincere gratitude for the in-kind assistance of Talon Vineyards and Winery, Lexington, KY during the execution of this project.

${ }^{1}$ Current address: Department of Horticultural Sciences, Texas A\&M University 2134 TAMU College Station, TX 77843-2133.

${ }^{2}$ To whom reprint requests should be addressed; e-mailkkurtural@csufresno.edu. et al., 2006). For example, 'Chambourcin' (Vitis vinifera $\times$ Vitis rupestris) produces a large number of fruitful shoots from noncount positions (Ferree et al., 2003; Kurtural et al., 2006). The fruitfulness of non-count buds is the primary cause of overcropping and ineffectiveness of balanced pruning (Kurtural et al., 2006; Pool et al., 1978). To remedy this problem and regulate cropping levels and cropload in several hybrid cultivars such as Chambourcin, Vidal blanc, and Seyval blanc, balanced pruning combined with cluster or berry thinning have been used together (Howell et al., 1987; Kaps and Cahoon, 1989; Kurtural et al., 2006).

Cluster thinning is a technique used to obtain the needed crop control in medium- and large-clustered interspecific hybrids (Kaps and Cahoon, 1989; Kurtural et al., 2006). Thinning to two clusters per shoot reduced yield but increased the total soluble solids of the grape juice at harvest and invigorated the vine in the following years in a number of French-American hybrid and $V$. vinifera cultivars (Bravdo et al., 1984; Nonnecke, 1980; Reynolds et al., 1986). Kurtural et al. (2006) reported acceptable crop reduction in 'Chambourcin' grapevines with a combination of $20+10$ balanced pruning formula and cluster thinning to 1.2 clusters per shoot where yield was reduced but fruit quality was improved in addition to maintaining pruning weight per vine. For 'Vidal blanc', cluster thinning to one cluster per shoot and a balanced pruning formula of $15+10$ was advised based on labor cost savings and minimized crop loss resulting from winter damage in Michigan (Howell et al., 1987). These results coupled with improved fruit quality and periderm browning of potted 'Chambourcin' led to a new concept, "balanced cropping," where both balanced pruning, cluster thinning, and shoot thinning are used together for crop adjustment of interspecific hybrids as well as $V$. vinifera cultivars that can also be achieved mechanically (Geller and Kurtural, 2013; Kurtural et al., 2006, 2013; Main and Morris, 2004; Miller et al., 1996; Terry and Kurtural, 2011).

Vine balance in vineyards is commonly measured with the Ravaz Index (RI). The RI is the ratio between yield and pruning weight (Ravaz, 1911). The RI estimates the leaf area required to ripen clusters on the vine. Cropload management ameliorates the ratio between reproductive and vegetative growth of the grapevine to sustain productivity while optimizing yield, fruit composition, and midwinter, primary bud cold hardiness. Dormancy in grapevines is induced by shorter daylengths and colder temperatures and is essential if the vine is to withstand colder temperatures (Dami et al., 2005). The ability of the vine to enter a dormant state and to withstand freezing may be directly linked to the ratio between reproductive sinks and vegetative sources (O'Daniel et al., 2012).

Growers in Kentucky have had to rely on viticultural information generated in Michigan and New York. However, macroclimatic conditions in these regions are characteristic 
of cool climate viticulture (Jackson and Schuster, 1987) with growing degree-days (GDD) of $1250 \mathrm{GDD}$ (base $10^{\circ} \mathrm{C}$ ) and 1275 GDD, respectively (Howell, 2001). Central Kentucky is characterized by warm climate viticulture with more than 2200 GDD accumulation (Kurtural et al., 2008). It was hypothesized that cropping targets for "Vidal blanc' were not similar in cool vs. warm climate conditions. The long, warm growing season in Kentucky coupled with the typical 500 to $635 \mathrm{~mm}$ precipitation received during the growing season make proper management more challenging than the cooler and shorter growing seasons in the northern United States where 'Vidal blanc' has traditionally been grown. The long season (greater than 200 frost-free days) promotes more shoot growth per week, and the amounts of rain and humidity are key factors for development of fungal diseases as well. Thus, guidelines are needed for the lower Midwest that take into account the longer, warmer, and wetter growing season and the cold winters with fluctuating January temperatures.

The goal of this study was to identify optimal combinations of balanced pruning and cluster thinning levels without adversely affecting yield components, fruit composition, and midwinter primary bud cold hardiness of 'Vidal blanc' for commercial production in central Kentucky and the lower midwestern United States. The specific objectives were to determine the effect of pruning and cluster thinning on canopy architecture, yield components, and berry composition of 'Vidal blanc' grapevines.

\section{Materials and Methods}

Plant material and study location. This study was conducted in a non-irrigated commercial vineyard in Lexington, KY, with own-rooted 'Vidal blanc' planted in 2001 on a Maury silt loam soil [a fine, mixed, active, mesic Typic Paleudalf (U.S. Department of Agriculture, 2011)] with $2.4 \times 4-\mathrm{m}$ (vine $\times$ row) spacing. Row orientation was north to south. The vines were trained to a $1.8-\mathrm{m}$ high bilateral cordon and were supplied with $38.5 \mathrm{~kg}$ nitrogen/ha annually. Pests were managed using an integrated pest management program according to University of Kentucky guidelines (Bordelon et al., 2006). The experiment was set up as a three $\times$ three factorial arrangement of pruning formula and cluster thinning treatments in a completely randomized design with four replications. Each experimental unit consisted of three vines. The same vines were used for all treatments in all years of the study. The treatments described below were applied beginning in 2005. Data collection started in 2006 to allow the vines to acclimate to the treatments described below.

Balanced pruning treatments. The dormant canes were long-pruned to five nodes each to an upper limit of 65 nodes per vine and prunings were weighed on a top-loading scale. The number of nodes to be left on each vine was then determined by the weight of prunings removed. Three levels of balanced pruning severity were applied: $20+10,30+$ 10 , and $40+10$. The first number refers to the number of buds left for the initial $454 \mathrm{~g}$ of pruned biomass and the second number to the number of buds retained for each additional $454 \mathrm{~g}$ of biomass. Pruned biomass was also divided into dead and living canes and weighed separately. Separation into the two categories was determined by visual inspection of wood and bud color. Vine size was calculated as total biomass divided by withinrow spacing or $2.4 \mathrm{~m}$.

Cluster thinning treatments. Three levels of cluster thinning severity were established at the modified Eichhorn-Lorenz scale stage 31 (3- to 5-mm berry size) in all years. The number of clusters per shoot and per vine was counted before thinning in both years. The cluster thinning treatments consisted of retaining one (thinned to cluster on first count node), two (thinned to clusters on first and second count nodes), or all clusters per shoot.

Phenology of key developmental events. Air temperature data from the University of Kentucky Agricultural Weather Center were used to calculate the mean daily temperature. GDD during each year were calculated starting 1 Apr. using a base temperature of $\left(10^{\circ} \mathrm{C}\right)$ with no upper limit. This permitted the description of phenological stages by both calendar date and GDD (Table 1).

Shoot, cluster counts, and canopy architecture. Two weeks after bud burst, shoots per vine and clusters per shoot and per vine were counted to measure canopy architecture variables as reported elsewhere (Kurtural et al., 2013). Briefly, the number of count shoots (borne from buds counted in the formula and retained at pruning greater than $5 \mathrm{~mm}$ distal to the base of the cane), noncount shoots (borne from basal buds less than $5 \mathrm{~mm}$ distal to the base of the cane or on wood older than 1 year and not counted in those left after pruning), and total shoots (count + noncount shoots) retained per vine were counted and recorded at this time. Indicators of canopy architecture measurements like count shoots per hectare, distance between shoots, and leaf layer number were measured as described by Smart (1985).

Yield components and berry composition. Fruit yield and cluster numbers for all treatments were measured on a single vine within each experimental unit during harvest. During both years, yield was divided into marketable and unmarketable fruit (fruit displaying greater than $30 \%$ disease damage or insect herbivory). However, in both years, there was no unmarketable fruit. All treatments were harvested on the same date. Harvest date was determined by the cooperating winery based on a target juice $\mathrm{pH}$ of 3.5. Average cluster weight was calculated by dividing yield by cluster number. The RI for each treatment was then calculated by dividing the yield per vine by the dormant pruning weights collected.

A random 100-berry sample was collected at harvest from each replicate, placed in a polyethylene bag, stored on ice, and analyzed within $24 \mathrm{~h}$. The samples were crushed by hand and the juice was placed in $100-\mathrm{mL}$ beakers. A 5-mL portion of each sample was used to determine the percent total soluble solids measured as ${ }^{\circ}$ Brix using a digital refractometer (Spec Scientific Ltd., Scottsdale, AZ) The juice $\mathrm{pH}$ was determined with a glass electrode and a $\mathrm{pH}$ meter (Model AR15; Fisher Scientific, Pittsburgh, PA). The acidity of each sample was determined by titrating to $\mathrm{pH} 8.2$ with $0.1 \mathrm{~N} \mathrm{NaOH}$ and expressed as $\mathrm{mg} \cdot \mathrm{L}^{-1}$ tartaric acid (TA).

Node maturity and lethal injury to primary buds $\left(L T_{50}\right)$ analysis. Node maturity was derived as the ratio of nodes displaying periderm browning vs. those that did not for each experimental unit. Data were collected by determining the number of buds with periderm browning from 10 randomly selected shoots per node per experimental unit. Measurements were made on 25 Sept. 2006 and on 9 Sept. 2007 before a killing frost and on 11 Nov. 2006 and 24 Nov. 2008 after the first killing frost.

The lethal temperature to kill $50 \%$ of the primary buds $\left(\mathrm{LT}_{50}\right)$ was determined by subjecting cuttings from dormant canes to a controlled freezing stress as described by O'Daniel et al. (2012) in early November of 2006 and mid-February of 2008. Dormant canes (6 to $10 \mathrm{~mm}$ diameter) were randomly selected from pooled samples from all vines of a given treatment stored on ice at $-4{ }^{\circ} \mathrm{C}$. Selected canes were pruned to three buds and bundled in groups of four cuttings for four replications and nine temperature evaluation

Table 1. Phenological progression of own-rooted 'Vidal blanc' in 2006 and 2007, in Lexington, KY.

\begin{tabular}{|c|c|c|c|c|c|}
\hline Phenology & Modified Eichhorn-Lorenz stage & Date in 2006 & Date in 2007 & $\mathrm{GDD}^{\mathrm{z}}$ accumulated 2006 & GDD accumulated 2007 \\
\hline Berries 3 to $5 \mathrm{~mm}^{\mathrm{y}}$ & 31 & 14 June & 11 June & 424 & 538 \\
\hline Veraison & 35 & 6 Aug. & 9 Aug. & 1208 & 1398 \\
\hline Killing frost & 43 & 15 Oct. & 21 Oct. & 1948 & 2405 \\
\hline
\end{tabular}

${ }^{\mathrm{z}}$ Cumulative growing degree-days (GDD) using the daily mean temperature minus a $10{ }^{\circ} \mathrm{C}$ base temperature. Mean daily temperatures: University of Kentucky Agricultural Weather Center (<http://www.agwx.ca.uky.edu $>)$.

${ }^{y}$ Cluster thinning treatments applied. 
points for each treatment [16 cuttings (48 buds total)/pruning treatment/temperature]. Progressive freeze treatments began at $0{ }^{\circ} \mathrm{C}$ and ended at $-40{ }^{\circ} \mathrm{C}$. Temperatures in the chamber were lowered by $-5{ }^{\circ} \mathrm{C}$ progressively for a 2-h ramp time and then held constant at that temperature for a $1-\mathrm{h}$ soak time. Samples from each temperature treatment were removed from the freeze chamber every $3 \mathrm{~h}$ at the completion of each soak time and allowed to thaw for $48 \mathrm{~h}$ at $2{ }^{\circ} \mathrm{C}$ before evaluation. Buds were dissected by making lateral cross-section cuts across the dormant bud with a razor blade, exposing the primary bud, which was examined for oxidative browning, an indicator of lethal injury (Stergios and Howell, 1972). Numbers of live or dead primary buds were recorded. The temperature at which $50 \%$ lethal injury $\left(\mathrm{LT}_{50}\right)$ occurred was estimated by fitting a sigmoidal nonlinear regression model \{logistic 4-P; $\mathrm{Y}=$ $\mathrm{a}+\mathrm{b} /\left[1+\operatorname{Exp}\left(\mathrm{c}-\mathrm{d}^{*} \mathrm{X}\right)\right]$, where $\mathrm{Y}=\%$ dead buds and $\mathrm{X}=$ temperature $\}$ to the data from each treatment using SAS Version 9.3 (SAS Institute Inc., Cary, NC) and then computing the predicted value from the regression equation. Estimated $\mathrm{LT}_{50}$ values were compared among treatments by two-way analysis of variance (ANOVA) as described below.

Statistical analyses. Data for all parameters were tested to verify if the assumptions of ANOVA were met using the Shapiro-Wilk test. Data that failed to meet the assumptions of ANOVA were $\log 10$ transformed and analyzed using the generalized linear model (GLM) procedure in SAS (Version 9.3; SAS Institute Inc.). The significance level was set at $\alpha=0.05$, and means were separated using Tukey's honestly significant difference test. Pruning formula and cluster thinning treatments were then tested for polynomial trends across treatment levels using the GLM procedure of SAS. For the transformed data, when the ANOVA showed significant differences, the mean separation test was conducted on the transformed data but non-transformed means were presented for ease in discussion. Interactions between year and treatments were tested and, whenever these interactions were significant $(P<0.05)$, analysis was conducted separately for each year.

\section{Results}

Canopy architecture. There was an interaction of year and pruning on the number of count shoots per hectare (Table 2). There were fewer count shoots per hectare in 2007 compared with 2006. Generally, as the severity of pruning increased (fewer nodes retained per vine), there were fewer shoots per hectare. The distance between shoots exhibited an interaction of year by pruning formula. The shoots were further apart in 2007 compared with 2006 . Generally, as the severity of pruning decreased (more nodes retained per vine), distance between shoots became closer. There was no effect of treatment or year on the leaf layer numbers. The cluster thinning treatments did not affect any of the canopy architecture variables measured.
Yield components. In 2006, the pruning formula treatments did not affect the number of clusters harvested, berry (data not shown) or cluster weight, or yield per vine (Table 3 ). However, in 2007, there was a linear response to the pruning formula applied where the number of clusters harvested increased with the decrease in the severity of pruning formula. The berry and cluster weight of 'Vidal blanc' did not respond to pruning formula treatments in 2007. There was a strong, linear response of clusters harvested per vine to cluster thinning in both years. As the severity of cluster thinning decreased (more clusters retained per shoot), there were more clusters harvested. Cluster thinning did not affect berry weight, but pruning formula interacted with cluster thinning on cluster weight in 2007 . The combination of the $20+10$ pruning formula

and retention of one cluster/shoot resulted in the greatest cluster weight compared with the combination of the $40+10$ pruning formula and the two + clusters/shoot cluster thinning treatment, which had the smallest cluster weight. Yield per vine declined linearly as the severity of cluster thinning increased in 2006 and 2007. There was no effect of experimental year on yield, but, in both years of the study, applying the one cluster/shoot treatment almost halved the yield per vine compared with leaving two+ clusters/shoot.

Fruit composition. There was an effect of experimental year on total soluble solids (TSS) of 'Vidal blanc' at harvest where it was slightly higher in 2007 than in 2006. However, neither pruning formula nor cluster thinning affected TSS or juice $\mathrm{pH}$ in either year (data not shown). The TA was affected

Table 2. Effect of pruning formula and cluster thinning on canopy architecture on own-rooted 'Vidal blanc' grapevine in 2006 and 2007 in Lexington, KY. ${ }^{\mathrm{z}}$

\begin{tabular}{|c|c|c|c|}
\hline Source of variation & Count shoots per hectare ${ }^{\mathrm{x}}$ & $\begin{array}{l}\text { Distance between } \\
\text { shoots }(\mathrm{cm})^{\mathrm{w}}\end{array}$ & Leaf layer number ${ }^{\mathrm{v}}$ \\
\hline Pruning formula ${ }^{\mathrm{y}}$ & & 2006 & \\
\hline $20+10$ & $71,960 \mathrm{~b}$ & $3.49 \mathrm{a}$ & 5.2 \\
\hline $30+10$ & $78,221 \mathrm{a}$ & $3.22 \mathrm{~b}$ & 6.2 \\
\hline $40+10$ & $76,850 \mathrm{ab}$ & $3.27 \mathrm{ab}$ & 5.7 \\
\hline$P$ & 0.0498 & 0.0444 & 0.3084 \\
\hline \multicolumn{4}{|l|}{ Trend analysis ${ }^{\mathrm{u}}$} \\
\hline Linear & 0.0655 & 0.0517 & 0.4203 \\
\hline Quadratic & 0.0954 & 0.0823 & 0.1978 \\
\hline \multicolumn{4}{|l|}{ Cluster thinning $^{t}$} \\
\hline 1 cluster/shoot & 75,076 & 3.35 & 5.6 \\
\hline 2 cluster/shoot & 76,195 & 3.32 & 5.7 \\
\hline $2+$ clusters/shoot & 75,759 & 3.32 & 5.8 \\
\hline$P$ & 0.9116 & 0.9473 & 0.9412 \\
\hline \multicolumn{4}{|l|}{ Trend analysis } \\
\hline Linear & 0.6923 & 0.7913 & 0.8171 \\
\hline Quadratic & 0.9598 & 0.8842 & 0.8139 \\
\hline Pruning $\times$ thinning $(P)$ & 0.3483 & 0.3540 & 0.1804 \\
\hline Pruning formula & & 2007 & \\
\hline $20+10$ & $41,818 \mathrm{c}$ & $6.05 \mathrm{a}$ & 4.0 \\
\hline $30+10$ & $49,557 \mathrm{~b}$ & $5.06 \mathrm{~b}$ & 4.5 \\
\hline $40+10$ & $62,805 \mathrm{a}$ & $4.00 \mathrm{c}$ & 5.3 \\
\hline$P$ & 0.0001 & 0.0001 & 0.2229 \\
\hline \multicolumn{4}{|l|}{ Trend analysis } \\
\hline Linear & 0.0001 & 0.0001 & 0.0948 \\
\hline Quadratic & 0.0630 & 0.8400 & 0.8778 \\
\hline \multicolumn{4}{|l|}{ Cluster thinning } \\
\hline 1 cluster/shoot & 52,094 & 4.93 & 4.0 \\
\hline 2 cluster/shoot & 52,764 & 4.92 & 5.3 \\
\hline $2+$ clusters/shoot & 49,322 & 5.26 & 4.4 \\
\hline$P$ & 0.0844 & 0.1009 & 0.2349 \\
\hline \multicolumn{4}{|l|}{ Trend analysis } \\
\hline Linear & 0.8680 & 0.9821 & 0.0992 \\
\hline Quadratic & 0.3761 & 0.3314 & 0.7011 \\
\hline Pruning $\times$ thinning $(P)$ & 0.3835 & 0.2938 & 0.3220 \\
\hline $\operatorname{Year}(P)$ & 0.0001 & 0.0001 & 0.7746 \\
\hline Year $\times$ pruning $(P)$ & 0.0002 & 0.0003 & 0.4457 \\
\hline Year $\times$ thinning $(P)$ & 0.9847 & 0.9921 & 0.2571 \\
\hline Year $\times$ pruning $\times$ thinning $(P)$ & 0.0027 & 0.0064 & 0.1845 \\
\hline
\end{tabular}

$\mathrm{z}_{\mathrm{n}}=4$. Values with different letter designations represent a significant mean separation according to Tukey's honestly significant different test at $P \leq 0.05$.

yPruning formula represents retaining 20,30, or 40 buds for each $454 \mathrm{~g}$ of dormant pruning weight plus 10 more for each additional $454 \mathrm{~g}$.

${ }^{\mathrm{x}}$ Count shoots per hectare $=$ count shoots per vine $\times$ vines per hectare.

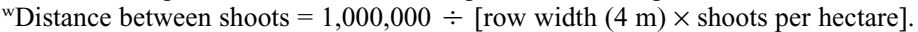

${ }^{v}$ Leaf layer number $=($ leaf area per shoot/shoot length $) \times[\sin ($ angle of shoot curvature $)] /$ distance between shoots.

uTrend analysis carried to the quadratic level using single df orthogonal contrasts.

${ }^{\mathrm{t}}$ Cluster thinning $=$ at modified Eichhorn-Lorenz scale stage 31, one cluster per shoot, two clusters per shoot, or all clusters were retained. 
Table 3. Effect of pruning formula and cluster thinning on yield components of own-rooted 'Vidal blanc' grapevine in 2006 and 2007 in Lexington, KY. ${ }^{\mathrm{z}}$

\begin{tabular}{|c|c|c|c|}
\hline Source of variation & Clusters/vine (no) & Cluster wt (g) & Yield $(\mathrm{kg} /$ vine \\
\hline Pruning formula & & 2006 & \\
\hline $20+10$ & 90 & 129 & 11.6 \\
\hline $30+10$ & 99 & 112 & 11.7 \\
\hline $40+10$ & 88 & 124 & 10.8 \\
\hline$P$ & 0.4872 & 0.3321 & 0.8433 \\
\hline \multicolumn{4}{|l|}{ Trend analysis ${ }^{\mathrm{x}}$} \\
\hline Linear & 0.8881 & 0.5909 & 0.6744 \\
\hline Quadratic & 0.3902 & 0.1386 & 0.7740 \\
\hline \multicolumn{4}{|l|}{ Cluster thinningw } \\
\hline 1 cluster/shoot & $62 \mathrm{~b}$ & 125 & $7.7 \mathrm{c}$ \\
\hline 2 cluster/shoot & $104 \mathrm{a}$ & 118 & $12.2 \mathrm{~b}$ \\
\hline $2+$ clusters/shoot & $111 \mathrm{a}$ & 124 & $14.2 \mathrm{a}$ \\
\hline$P$ & 0.0001 & 0.8421 & 0.0035 \\
\hline \multicolumn{4}{|l|}{ Trend analysis } \\
\hline Linear & 0.0001 & 0.5459 & 0.0101 \\
\hline Quadratic & 0.0013 & 0.6843 & 0.0067 \\
\hline Pruning $\times$ thinning $(P)$ & 0.5068 & 0.7755 & 0.7515 \\
\hline Pruning formula & & 2007 & \\
\hline $20+10$ & $73 \mathrm{~b}$ & 154 & 11.2 \\
\hline $30+10$ & $82 \mathrm{~b}$ & 142 & 11.4 \\
\hline $40+10$ & $99 \mathrm{a}$ & 137 & 13.4 \\
\hline$P$ & 0.0003 & 0.0990 & 0.0538 \\
\hline \multicolumn{4}{|l|}{ Trend analysis } \\
\hline Linear & 0.0493 & 0.0744 & 0.2050 \\
\hline Quadratic & 0.7447 & 0.6792 & 0.5548 \\
\hline \multicolumn{4}{|l|}{ Cluster thinning } \\
\hline 1 cluster/shoot & $48 \mathrm{c}$ & $156 \mathrm{a}$ & $7.5 \mathrm{c}$ \\
\hline 2 cluster/shoot & $96 \mathrm{~b}$ & $136 \mathrm{~b}$ & $12.9 \mathrm{~b}$ \\
\hline $2+$ clusters/shoot & $110 \mathrm{a}$ & $140 \mathrm{ab}$ & $15.5 \mathrm{a}$ \\
\hline$P$ & 0.0001 & 0.0425 & 0.0001 \\
\hline \multicolumn{4}{|l|}{ Trend analysis } \\
\hline Linear & 0.0001 & 0.0371 & 0.0001 \\
\hline Quadratic & 0.0013 & 0.4641 & 0.0001 \\
\hline Pruning $\times$ thinning $(P)$ & 0.4738 & 0.0306 & 0.0802 \\
\hline Year $(P)$ & 0.4751 & 0.0001 & 0.9954 \\
\hline Year $\times$ pruning $(P)$ & 0.5547 & 0.9954 & 0.9948 \\
\hline Year $\times$ thinning $(P)$ & 0.1259 & 0.7457 & 0.7413 \\
\hline Year $\times$ pruning $\times$ thinning $(P)$ & 0.5561 & 0.8324 & 0.5478 \\
\hline
\end{tabular}

${ }^{z} \mathrm{n}=4$. Values with different letter designations represent a significant mean separation according to Tukey's honestly significant different test at $P \leq 0.05$.

yPruning formula represents retaining 20,30, or 40 buds for each $454 \mathrm{~g}$ of dormant pruning weight plus 10 more for each additional $454 \mathrm{~g}$.

${ }^{x}$ Trend analysis carried to the quadratic level using single $\mathrm{df}$ orthogonal contrasts.

${ }^{\mathrm{w}}$ Cluster thinning $=$ at modified Eichhorn-Lorenz scale stage 31, one cluster per shoot, two clusters per shoot, or all clusters were retained.

by an interaction of year and cluster thinning. In general, the TA was higher in 2007 than in 2006. Furthermore, leaving two clusters/shoot in 2007 resulted in the highest TA at harvest compared with all year and any other cluster thinning treatment.

Node maturation, midwinter primary bud cold hardiness, pruning weight, and Ravaz Index. There was an interaction of year and cluster thinning on node maturation when measured at pre-killing frost (Table 4). Retaining one cluster per shoot increased mature nodes per shoot in 2007 compared with all year and cluster thinning combinations. There was no effect of pruning or cluster thinning on node maturation per shoot when measured post-killing frost (data not shown). The lethal temperature to kill $50 \%$ of the primary buds $\left(\mathrm{LT}_{50}\right)$ when measured in winter was affected by the interaction of year and cluster thinning. Generally, primary buds displayed greater ability to withstand colder temperatures in 2006 compared with 2007. In 2006, there was no effect of pruning formula on $\mathrm{LT}_{50}$ of pruning severity. In both years of the study, the two clusters/shoot treatment had the greatest mature wood pruning weight. However, the dieback wood pruning weight was not influenced by the cluster thinning treatments applied. The pruning weight (mature wood + dieback wood weight) was unaffected by the pruning formula treatments. The pruning weight, however, declined linearly with the increase in the number of clusters retained per shoot in both years of the study. The interaction of experimental year and pruning formula affected the RI of 'Vidal blanc'. The RI was slightly lower in 2007 with the $20+10$ pruning formula and with the $40+10$ pruning formula in 2006 . The RI was affected by the cluster thinning treatments in both years of the study, increasing linearly with the decrease in the severity of cluster thinning. Leaving two + clusters/shoot resulted in the greatest RI in both years of the study.

\section{Discussion}

Canopy architecture. The study site was unseasonably cool in 2006, accumulating less than 2200 GDD. Furthermore, the study area also witnessed a historic freeze event in the spring of 2007 when air temperatures dropped below $-5.5^{\circ} \mathrm{C}$ for five consecutive nights on 7 Apr. through 12 Apr. 2007 preceded by an early, warm spring, which led to budbreak and leaf development a week before the dates in 2006. Therefore, there was significant shoot damage before the budbreak that generated the components of yield from the budbreak date reported in Table 1. Nevertheless, the number of count shoots per hectare and the distance between the shoots along the cordon responded in both years linearly to the pruning formula treatments as reported by Smart (1985) and Terry and Kurtural (2011). Severe pruning reduced the number of shoots exposed per hectare in both years as observed by Kurtural et al. (2006). Consequently, the distance between shoots along the cordon was further apart in the more severe pruning treatment, similar to that reported by Geller and Kurtural (2013). The effects of year and the interaction of year and pruning formula are explained by the freeze event that occurred in April of 2007. It was not surprising to see that distance between shoots was further apart in 2007 compared with 2006 as a consequence of secondary buds and noncount buds bursting, resulting in fewer count shoots per hectare in 2007. Although shoot density varied considerably depending on the severity of pruning, the leaf layer numbers were unaffected. This was a result of vegetative compensation occurring in warm climates where dormant pruning alone is a rough regulator of canopy architecture (Kurtural et al., 2013). The lack of a horticultural response to number of leaf layers likely stemmed from more sunlight available to the non-count positions on the cordon, generating many laterals and non-count shoots and a similar leaf area with the severe pruning formula when compared 
Table 4. Effect of pruning formula and cluster thinning on percent mature nodes post-harvest, midwinter primary bud cold hardiness, mature wood pruning weight, pruning weight, and Ravaz Index of own-rooted 'Vidal blanc' in 2006 and 2007 in Lexington, KY."

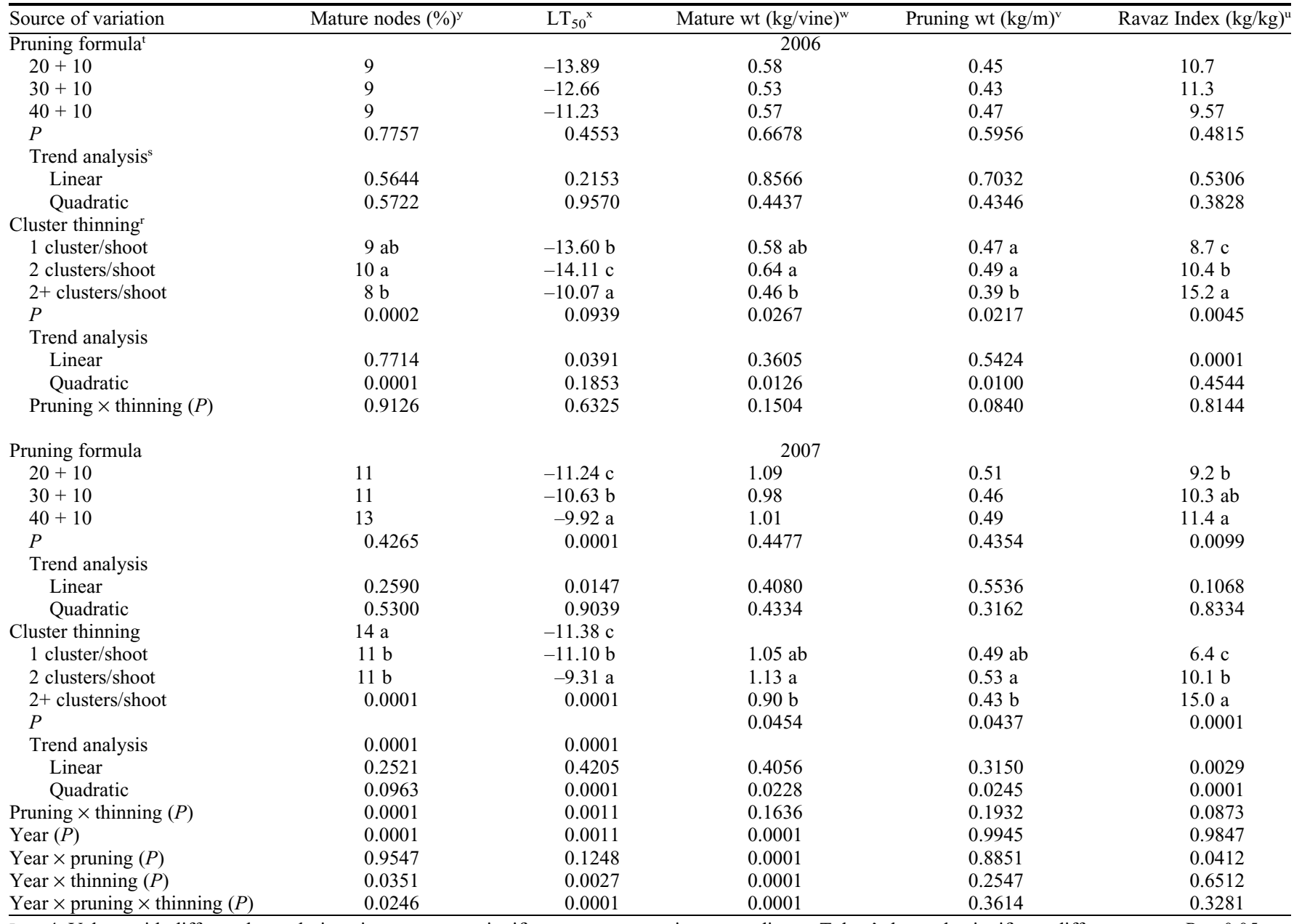

${ }^{\mathrm{z}} \mathrm{n}=4$. Values with different letter designations represent significant mean separations according to Tukey's honestly significant different test at $P \leq 0.05$.

yPercent mature nodes as measured by periderm browning one week post-harvest but before a killing frost.

${ }^{\mathrm{x}} \mathrm{LT}_{50}=$ lethal temperature at which $50 \%$ of the primary buds are killed as measured by oxidative browning.

${ }^{\mathrm{w}}$ Mature weight $=$ weight of live wood taken during dormant pruning.

${ }^{\mathrm{v}}$ Pruning weight $/ \mathrm{m}=$ total pruning weight $/ 2.4 \mathrm{~m}$ (vine spacing within row).

"Ravaz Index $=$ [yield per vine $(\mathrm{kg}) \div$ pruning weight per vine $(\mathrm{kg})]$.

tPruning formula represents retaining 20,30, or 40 buds for each $454 \mathrm{~g}$ of dormant pruning weight plus 10 more for each additional $454 \mathrm{~g}$.

${ }^{s}$ Trend analysis carried to the quadratic level using single df orthogonal contrasts.

${ }^{\mathrm{r}}$ Cluster thinning = at modified Eichhorn-Lorenz scale stage 31, one cluster per shoot, two clusters per shoot, or all clusters were retained.

with the less severe pruning formula, noted by Bernizzoni et al. (2011) and Geller and Kurtural (2013).

Yield components. Balanced pruning alone did not result in adequate and consistent yield control in a interspecific hybrid as others reported (Fisher et al., 1977; Kurtural et al., 2006) unless followed by cluster thinning. Balanced pruning provided yield control only when count shoots per hectare varied by $16 \%$ for each additional 10 nodes retained per fraction of $454 \mathrm{~g}$ of dormant pruning weight. Consequently, the number of clusters per vine increased by $\approx 10 \%$ among pruning formula in a linear response to the reduction of pruning severity. However, the berry weight was unaffected by balanced pruning in either year of the study. The lack of response in berry weight to pruning formula resulted in no effect on cluster weight in either year as reported elsewhere (O'Daniel et al., 2012). Therefore, balanced pruning alone was not sustainable for
'Vidal blanc'. Similar conclusions were reported for 'DeChaunac' and 'Chambourcin' where unthinned vines have often suffered from low pruning weight retention and winter injury (Fisher et al., 1977; Kurtural et al., 2006).

In 2006 and 2007, the number of clusters retained on the vines explained $73 \%$ and $77 \%$ of the total variance in yield, respectively. This finding was corroborated by previous observations (Kurtural et al., 2006) of interspecific hybrids. Therefore, yield was primarily affected by the numbers of clusters retained on the vine. There was an effect of experimental year on \%TSS and TA at harvest, likely a result of the late development of fruit resulting from the freeze in 2007.

Fruit composition. Increasing canopy shade raises the $\mathrm{pH}$ and potassium in must and wine (Smart, 1985; Smart and Robinson, 1991). Canopy shading also leads to lower sugar accumulation and uneven ripening in clusters. Although canopy architecture was affected by pruning formula as described previously, there were no treatment effects on fruit composition. In a 2-year study of 'Traminette' on the same training system conducted in southern Illinois (Dami and Ji, 2008), which has a similar climate to Kentucky, ${ }^{\circ}$ Brix was higher, $\mathrm{pH}$ was lower, and TA was intermediate to the levels observed in Kentucky. Because harvest was in early September both years as a result of site restrictions imposed by the winery for this study, berry ripening was perhaps limited, contributing to the differences with the other studies of interspecific hybrids.

Node maturation and primary bud cold hardiness. Low temperatures, especially midwinter advective freezes, are the limiting factor in expansion of acreage and grapevine productivity for several grape-growing regions in the midwestern United States (Howell, 2001; O'Daniel et al., 2012). The cold midwinter 
temperatures in Kentucky are often the determining factor in deciding which cultivars to plant (Kurtural et al., 2008). The lack of a response by the pre-killing frost percent mature nodes to pruning formula application was previously reported for interspecific hybrids in Kentucky (O'Daniel et al., 2012). The present study reports an increase in percent mature nodes in both years when measured at pre-killing frost with decreasing crop level. This observation is important because practices that control crop size over multiple years would favor resistance to cold temperatures as reported by others (Howell et al., 1987; O'Daniel et al., 2012). When percent mature nodes were measured after the killing frost, there was a lack of treatment effect. However, whether pre- or post-killing frost, the percent mature nodes were above $60 \%$ in both years of the study. This was an artifact of the long growing season in Kentucky; periderm browning should not be an issue for growers of this cultivar if cluster thinning is applied and proper periderm browning is evident before occurrence of the killing frost in warm regions. Taken together with the $\mathrm{LT}_{50}$ data, cropload management with pruning formula and cluster thinning was beneficial for primary bud cold hardiness of 'Vidal blanc'. The several degree improvements in the primary bud coldhardiness of 'Vidal blanc' with retention of one or two clusters per shoot would be important for the region. Previously, Howell et al. (1987) recommended a combination of $15+10$ pruning formula while retaining one cluster per shoot. Our results, although they confirm this finding, also revealed that a higher bud load, using a $30+10$ pruning formula with two clusters per shoot resulting in a larger crop, can be carried without much detriment to primary bud cold hardiness or percent mature nodes.

Pruning weight and Ravaz Index. It was evident that fruit production depressed vine capacity as 'Vidal blanc' adjusted to the treatments (Keller, 2010). Perhaps the most interesting finding of this trial was the quadratic response of mature wood weight and pruning weight per meter of row to cluster thinning. Pruning weight would be expected to decline linearly as fruit production depressed vine capacity (Geller and Kaan Kurtural, 2013; Kurtural et al., 2006; Terry and Kurtural, 2011). Conversely, in both years of the study, retaining the correct number of clusters (two clusters/shoot in this case) improved mature pruning weight and total pruning weight. Furthermore, in both years, pruning weight per meter of row, although never below the recommended rate of $0.30 \mathrm{~kg} \cdot \mathrm{m}^{-1}$ of row (Kurtural et al., 2006), was the greatest at two clusters/shoot. Other interspecific hybrids such as 'Chambourcin', 'Seyval blanc', and 'Traminette' have shown that vine size greater than $0.59 \mathrm{~kg} \cdot \mathrm{m}^{-1}$ of row was a sign of excessive vine growth (Kurtural et al., 2006; O'Daniel et al., 2012; Reynolds and Wardle, 1994). This indicated that a pruning weight per meter of row needs to be between 0.30 $\mathrm{kg} \cdot \mathrm{m}^{-1}$ and $0.59 \mathrm{~kg} \cdot \mathrm{m}^{-1}$ of row, and this range was achievable at two clusters/shoot without any detrimental effects on pruning weight.

An ideal RI range of 5 to $10 \mathrm{~kg}$ yield per kilogram of pruning weight may be optimal while maintaining vine capacity (Kliewer and Dokoozlian, 2005; Terry and Kurtural, 2011) in a warm climate. The linear increase in RI seen in this trial was not surprising. As more crop was retained, RI would undoubtedly increase (Geller and Kaan Kurtural, 2013). However, the optimum RI value of $\approx 10.0 \mathrm{~kg} \cdot \mathrm{kg}^{-1}$ was only achieved with the combination of $30+10$ pruning formula and two clusters/shoot treatment in both years of the trial without any detrimental effects on primary bud cold hardiness or a severe decline in pruning weight per meter of row. This finding, coupled with the longer and warmer season witnessed in central Kentucky, indicated that a larger crop could be retained in this region compared with the Michigan recommendation of $15+10$ pruning formula with one cluster per shoot (Howell et al., 1987).

\section{Conclusion}

Pruning severity was not as effective alone as it was with its combination with cluster thinning for 'Vidal blanc' in the lower midwestern United States. Primary bud LT $\mathrm{L}_{50}$, pruning weight, and yield components all responded favorably when pruning was combined with cluster thinning. The $30+10$ pruning formula combined with retention of two clusters/shoot was the most likely to generate a less dense canopy and withstand coldest temperatures with no detrimental effects on fruit composition. Although the yields per vine from this cropload management combination was less than with less severe pruning and cluster thinning combinations, it was proven with this trial that some grower intervention is essential after dormant pruning for withstanding the low winter temperatures in this warm region.

A number of horticulturally important variables were measured in response to balanced pruning and cluster thinning. At the culmination of the trial, the vines were in balance with the $30+10$ pruning formula and retention of two clusters/shoot. Thus, this study showed that 'Vidal blanc' responded uniquely in several key aspects of growth, yield, and cold hardiness to cropload management and was both cold hardy and productive under the long, warm growing season associated with the lower midwestern United States.

\section{Literature Cited}

Bernizzoni, F., S. Civardi, M. Van Zeller, M. Gatti, and S. Poni. 2011. Shoot thinning effects on whole season photosynthesis and vine performance in Vitis vinifera L. cv. Barbera. Austral. J. Grape and Wine. Res. 17:351-357.

Bordelon, B., M. Ellis, and R. Foster. 2006 Midwest small fruit and grape spray guide. University of Kentucky, Extension Bulletin ID94. Purdue, IN
Bravdo, B., Y. Hepner, C. Loinger, S. Cohen, and H. Tabacman. 1984. Effect of crop level on growth, yield and wine quality of a high yielding 'Carignane' vineyard. Amer. J. Enol. Viticult. 35:247-252.

Dami, I., B. Bordelon, D.C. Ferree, M. Brown, M.A. Ellis, R.N. William, and D. Doohan. 2005. Midwest grape production guide. The Ohio State University Extension Bulletin 919. 05.

Dami, I.E. and T. Ji. 2008. Characterization of free flavor compounds in Traminette grape and their relationship to vineyard training system and location. J. Food Sci. 73:262-267.

Ferree, D.C., G.A. Cahoon, D.M. Scurlock, and M.V. Brown. 2003. Effect of time of cluster thinning on grapevines. Small Fruit Rev. 2:314.

Fisher, K.H., O.A. Bradt, J. Wiebe, and V.A. Kirks. 1977. Cluster thinning 'de Chaunac' French hybrid grapes improves vine vigor and fruit quality in Ontario. J. Amer. Soc. Hort. Sci. 102:162-165.

Geller, J.P. and S. Kaan Kurtural. 2013. Mechanical canopy and crop-load management of Pinot gris in a warm climate. Amer. J. Enol. Viticult. 64:65-73.

Howell, G.S. 2001. Sustainable grape productivity and the growth-yield relationship: A review. Amer. J. Enol. Viticult. 52:165-174.

Howell, G.S., T.K. Mansfeld, and J.A. Wolpert 1987. Influence of training system, pruning severity and thinning on yield, vine size, and fruit quality of 'Vidal Blanc' grapevines. Amer. J. Enol. Viticult. 38:105-112.

Jackson, D. and D. Schuster. 1987. The production of grapes and wines in cool climates. Butterworths, Wellington, New Zealand.

Kaps, M.L. and G.A. Cahoon. 1989. Berry thinning and cluster thinning influence vegetative growth, yield, fruit composition and net photosynthesis of 'Seyval Blanc' grapes. HortScience 114:20-24.

Keller, M. 2010. The science of grapevines - Anatomy and physiology. Academic Press, Burlington, MA.

Kliewer, W.M. and N.K. Dokoozlian. 2005. Leaf area/crop weight ratios of grapevines: Influence on fruit composition and wine quality. Amer. J. Enol. Viticult. 56:170-181.

Kurtural, S.K., I.E. Dami, and B.H. Taylor. 2006 Effects of pruning and cluster thinning on yield and fruit composition of Chambourcin grapevines. HortTechnology 16:233-240.

Kurtural, S.K., L. Wessner, and G. Dervishian. 2013. Vegetative compensation response of a procumbent cultivar (Vitis vinifera cv. Syrah) under mechanical canopy management. HortScience 48:576-583.

Kurtural, S.K., P.E. Wilson, and I.E. Dami. 2008 Kentucky viticultural regions and suggested cultivars. University of Kentucky Extension Bulletin HO-88. Lexington, KY.

Main, G.L. and J.R. Morris. 2004. Leaf-removal effects on Cynthiana yield, juice composition, and wine composition. Amer. J. Enol. Viticult. 55:147-152.

Miller, D.P., G.S. Howell, and J.A. Flore. 1996. Influence of shoot number and crop load on potted Chambourcin grapevines. I. Morphology and dry matter partitioning. Amer. J. Enol. Viticult. 47:380-388

Nonnecke, G.R. 1980. The influence of cluster thinning and shoot-tip removal on 'Seyval' grapevine. PhD diss., Ohio State Univ., Columbus, $\mathrm{OH}$.

O'Daniel, S.B., D. Archbold, and S.K. Kurtural. 2012. Effects of balanced pruning severity on 
Traminette (Vitis spp.) in a warm climate. Amer. J. Enol. Viticult. 63:284-290.

Pool, R.M., C. Pratt, and H.D. Hubbard. 1978. Structure of base buds in relation to yield of grapes. Amer. J. Enol. Viticult. 29:36-41.

Ravaz, M.L. 1911. L'effeuellage de la vigne. Annales d L'Ecole Nationale d'argriculture de Montpellier 11:216-244.

Reynolds, A.G., R.M. Pool, and L.R. Mattick. 1986. Effect of shoot density and crop control on growth, yield, fruit composition and wine quality of 'Seyval' grapes. J. Amer. Hort. Soc. Sci. 111:55-63.
Reynolds, A.G. and D.A. Wardle. 1994. Impact of training system and vine spacing on vine performance and berry composition of Seyval blanc. Amer. J. Enol. Viticult. 45:444451.

Smart, R.E. 1985. Principles of grapevine canopy microclimate manipulation with implications for yield and quality. A review. Amer. J. Enol. Viticult. 36:230-239.

Smart, R.E. and M. Robinson. 1991. Sunlight into wine. A handbook for wine grape canopy management. Winetitles, Adelaide, Australia.
Stergios, B.G. and G.S. Howell. 1972. Evaluation of viability tests for cold stressed plants. J. Amer. Soc. Hort. Sci. 98:325-330.

Terry, D. and S.K. Kurtural. 2011. Achieving vine balance of Syrah with mechanical canopy management and regulated deficit irrigation. Amer. J. Enol. Viticult. 62:426437.

U.S. Department of Agriculture. 2011. Soil survey staff Official soil series descriptions. USDANRCS. 1 Apr. 2011. <http://soils.usda.gov/ technical/classification/osd/index.html>. 